\title{
Journal Perspectives, Publication Rates, And Textbook Preferences Of Accounting Information Systems Faculty
}

Mark G. Simkin, (E-mail: simkin@unr.edu), University of Nevada, Reno Stephen Kerr, University of Nevada, Reno

Richard Mason, University of Nevada, Reno

\begin{abstract}
This paper describes the journal preferences, publishing perspectives, publication rates, and textbook preferences of those individuals who responded to a survey of all accounting systems faculty now working at AACSB-accredited institutions. The top-rated journals included the Journal of Information Systems and the International Journal of Accounting Information Systems, although many "non-accounting" journals were also highly rated. In addition, most of the respondents believe that (1) publishing in first or second-tier journals is important for tenure decisions, and that (2) it is even more important to publish in quality journals when applying for promotion to full professor. The publication productivity of the AIS faculty responding to the survey varied widely, but the median rate of one, blind-refereed article per year describes both male and female researchers. Finally, the vast majority of the survey respondents felt that the "systems area" in accounting is isolated, or not as well respected, as other accounting sub-disciplines.
\end{abstract}

\section{INTRODUCTION}

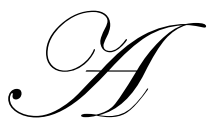

growing body of literature now documents the importance of computer skills and the need for a greater knowledge of information technology in performing accounting work (Jackson and Cherrington, 2002; Theuri and Guinn, 1998; Jolly, et. al., 1995). Yet, despite the increasing importance of computers in accounting systems, it has only been recently that "accounting information systems" has emerged as a separate area within the accounting discipline. Testimony to the importance of the "systems area" is the widespread implementation of AIS courses within already established accounting curricula, and in some cases, new rules requiring students to take one or more AIS courses within the accounting or even general core course requirements of the university (Lont and MacGregor, 1996; Wilson, 1996).

Paralleling the increasing interest in accounting systems is the growing number of university faculty who teach AIS classes. But the literature about such individuals is mostly notable for its absence. Thus, little is known about systems faculty - for example, what journals are important to them, how their publication rates compare to other business faculty, or even what textbooks they use in their classes.

To answer these questions, the authors conducted a survey of those faculty currently teaching AIS classes. Appendix A contains a copy of the survey instrument. To limit its scope, the author sent a questionnaire to each of the individuals listed in Hasselback's 2002-2003 Directory of Accounting Faculty who satisfied the following two criteria: (1) the individual listed "systems" as a primary research or teaching area, and (2) the individual worked at a school whose accounting program was separately accredited by the Association to Advance Collegiate Schools of Business (AACSB). Approximately 275 faculty members satisfied both these requirements - a small population in light of the acknowledged importance of the systems area. 


\section{RESULTS}

Survey respondents answered anonymously, although individuals were given the opportunity to provide their email addresses if they desired a copy of the results. The authors received a total of 51 usable responses, representing a 19 percent response rate. Not every person answered every question, so the total number of responses to any of the questions discussed below may not total " $51 . "$

\section{Demographics Of Respondents}

Of the respondents, 22 were female, 28 were male, and one respondent failed to indicate a gender. As shown in Table 1, the professorial ranks of the respondents were fairly uniformly distributed: 15 assistant professors, 19 associate professors, and 14 full professors. However, as demonstrated in the table, the distribution of gender by rank was not uniform: the male respondents tended to have higher rank than the female respondents. This suggests that, like such other accounting sub-disciplines as managerial accounting or financial accounting, there are more females in the lower academic ranks.

The survey instrument also asked respondents to indicate how much time had passed since receiving their doctorates. The minimum time was 2 years, the maximum time was 34 years, and the average was almost exactly 12 years.

Table 1: Rank and Gender of Survey Respondents

\begin{tabular}{|c|c|c|c|}
\hline RanklGender & Male & Female & Total \\
\hline Lecturer & 1 & 1 & 12 \\
\hline Assistant Professor & 3 & 12 & 19 \\
\hline Associate Professor & 14 & 5 & 14 \\
\hline Full Professor & 10 & 4 & \\
\hline
\end{tabular}

\section{The Importance Of Journal Quality In Promotion And Tenure Decisions}

A considerable body of knowledge both within and beyond the accounting discipline documents the concern for "journal quality" - in particular, the importance of publishing research in quality academic outlets (Christensen, et. al., 2002, Hasselback, et. al., 2000; Read, et. al., 1998; Zivney, et. al., 1995, Maranto and Streuly, 1994, Campbell and Morgan, 1987; Jolly, et. al., 1995). Accordingly, the current survey posed two questions related to this concern: (1) "When applying for tenure, how important is the quality of the journals in which an applicant has published?" and (2) "When applying for promotion to full professor, how important is the quality of the journals in which an applicant has published?" The responses to these two questions are summarized in Table 2.

Table 2: The Importance Of Journal Quality In Tenure And Promotion Decisions

\begin{tabular}{|c|c|c|c|c|}
\hline & Not Important & Somewhat Important & Very Important & Don't Know \\
\hline Tenure decisions & 1 & 18 & 29 & 0 \\
\hline $\begin{array}{c}\text { Promotion to full } \\
\text { professor decisions }\end{array}$ & 1 & 14 & 32 & 2 \\
\hline
\end{tabular}

Table 2 suggests that almost all AIS faculty feel that the quality of the journals in which an applicant has published is either "somewhat important" or "very important" in both tenure and promotion (to full professor) decisions. The table also suggests that a clear majority feel that journal quality is "very important" for such decisions.

Questions 13 and 14 of the survey asked two additional questions related to tenure decisions: (1) "Can a tenure-track faculty member get tenure at your school without publishing any articles in top-tier academic journals," 
and (2) "Can a tenure-track faculty member get tenure at your school without publishing any articles in first- or second-tier academic journals?" Table 3 summarizes the answers to these two questions.

Table 3: Publication Requirements Necessary For Tenure At Respondent's School

\begin{tabular}{|l|c|c|c|}
\hline & Yes & No & Maybe/Don't know \\
\hline Publications in top-tier journals required? & 28 & 20 & 1 \\
\hline Publications in first- or second-tier journals required? & 10 & 35 & 2 \\
\hline
\end{tabular}

The figures in Table 3 suggest that the respondents were split on whether or not tenure applicants had to publish in top-tier academic journals - 28 said "yes" while 20 said "no." The answers to the second question were much more definitive: a clear majority felt that it was not possible to obtain tenure without publications in first- or second-tier academic journals. (One person who answered "maybe" to this second question noted that it might be possible in other disciplines in her school, but that she "wasn't sure.")

\section{Journal Preferences}

Because the accounting information systems area is relatively new, so are the journals that specialize in publishing articles about AIS topics. In the past, this has caused problems for AIS faculty, including misunderstandings about the relationship of AIS to both accounting and information systems audiences, the relevance of systems articles to accounting theory and practice, the quality of the new publication outlets, and tenure and promotion decisions that depend upon a comprehensive understanding of the publication outlets available to candidates (Herron and Hall, 2004; Daigle and Arnold, 2000; Rowley, 1991).

To address these issues, Question 8 of the survey instrument asked respondents to name the three journals they considered most important in the AIS area. The directions also noted that "these can be practitioner or academic journals, and need not be accounting journals." This open-ended format deviates from the manner in which several prior researchers have measured "journal preferences," most of whom have restricted respondents to ranking journals on "approved lists" of publications that were used in earlier studies. However, this format also gave respondents more latitude and, at least in our survey, provided some surprising findings. Table 4 lists the top ten journals, as ranked by the most citations in this question.

By a wide margin, the Journal of Information Systems was the top-rated AIS journal. More surprising was the fact that the number two journal was MIS Quarterly, the number four journal was Information Systems Research, and the number five journal was the Journal of Management Information Systems - journals that are more-closely associated with "computer information systems" than "accounting." This finding also provides additional evidence that accounting scholars frequently value, and sometimes publish in, journals that are "outside" the accounting discipline (see Christensen, et. al, 2002). An additional 18 journal titles were mentioned by the survey respondents, but none more than twice.

These journal rankings contrast somewhat with those of Daigle and Arnold (2000), who also attempted to identify the top journals in the AIS area. Using the ratings of 25 "top AIS researchers," these authors assigned the top ranks to the following seven journals: (1) the Accounting Review, (2) the Journal of Accounting Research, (3) MIS Quarterly, (4) Information Systems Research, (5) Management Science, (6) Contemporary Accounting Research, and (7) Administrative Science Quarterly. Again, many of the same "non-accounting" journals (e.g., Information Systems Research and MIS Quarterly) were among the top contenders. That study ranked the Journal of Management Information Systems fifteenth and Advances in Accounting Information Systems twenty-second. (The other journals listed in Table 4 were not ranked in that study.) 
Table 4: Top Ranked Journals by AIS Instructors

\begin{tabular}{|l|c|}
\hline \multicolumn{1}{|c|}{ Journal } & Respondents Identifying This Journal as Important \\
\hline Journal of Information Systems & 36 \\
\hline MIS Quarterly & 18 \\
\hline International Journal of AIS & 12 \\
\hline Information Systems Research (ISR) & 7 \\
\hline Journal of Management Information Systems (JMIS) & 6 \\
\hline Accounting Review & 5 \\
\hline Journal of Accountancy & 5 \\
\hline Review of Business Information Systems & 2 \\
\hline Advances in AIS & 4 \\
\hline Decision Sciences & 4 \\
\hline
\end{tabular}

\section{Publication Rates Of AIS Faculty}

In addition to asking about the importance of publishing articles in the discipline, the authors also asked respondents how many years had passed since they had acquired their doctorate and also how many articles they had published in blind-refereed journals since acquiring their doctorate. The answers to these questions enabled the authors to compute publication rates (average number of publications per year) for each of the respondents.

\section{Average, Minimum, and Maximum Publication Rates for AIS Faculty}

Table 5 provides some statistics derived from the respondents' answers to the survey's publication questions. It shows that the total number of articles published by an individual AIS faculty member varied widely, ranging from a minimum of " 1 article" to a maximum of "70 articles." However, this productivity is consistent with the fact that the number of years since the respondents had received their doctorates also varied widely-from a minimum of 2 years to a maximum of 34 years.

Probably the statistic of greatest interest in Table 5 is the mean publication rate of "1.06 articles per year." This figure is consistent with the values of ".99" (for associate professors) and "1.03" (for full professors) computed by Englebrecht, et. al. (1994), and is almost identical to the average publication rate of "1.03" for researchers in other accounting sub-disciplines that the authors computed in a larger meta-research study (citation provided upon paper's acceptance).

Table 5: Average, Minimum, And Maximum Publication Rates For AIS Faculty

\begin{tabular}{|l|c|c|c|c|}
\hline & Number of articles & $\begin{array}{c}\text { Years since receiving } \\
\text { doctorate }\end{array}$ & Survey Results: & Publication Rate: \\
\hline Average: & 13.2 & 12.0 & Average ${ }^{1}:$ & 1.06 \\
\hline Minimum: & 1 & 2 & Minimum rate: & 0.00 \\
\hline Maximum: & 70 & 34 & Maximum rate: & 7.71 \\
\hline
\end{tabular}

This study's average publication rate of "1.06 articles per year" is considerably higher than the publication rate of less than .3 articles per year (for all accounting faculty) which the authors derived from a recent study by Christensen, et. al (2002), the rate of "0.07" (for all accounting faculty) reported in Buchheit, et. al, (2004), or the highest average publication rate of ".31" reported in Hasselback, et. al., (2000). These differences are probably best explained by differences in methodology - for example, the fact that all three of these parallel studies limited themselves to articles appearing in selected accounting journals.

\footnotetext{
${ }^{1}$ This value was computed by averaging the publication rates themselves, not by dividing the average number of articles by the average years since receiving a doctorate.
} 


\section{Publication Rates by Professorial Rank}

A number of earlier studies have also discerned different publication rates among the three professorial ranks -i.e., assistant professor, associate professor, and full professor (see, for example, Englebrecht, et. al., 1994, or Campbell and Morgan, 1987). How do AIS publication rates vary by rank? Table 6 provides relevant statistics.

Table 6: Publication Rates (Articles/Year) By Academic Rank

\begin{tabular}{|l|c|c|c|}
\hline & Assistant Professor & Associate Professor & Full Professor \\
\hline Average: & 0.92 & 1.37 & 1.60 \\
\hline Minimum: & 0.00 & 0.09 & 0.71 \\
\hline Maximum: & 3.00 & 7.71 & 5.88 \\
\hline
\end{tabular}

The figures in Table 6 show that publication rates vary widely by rank, and also within ranks, for AIS faculty. The first row of figures provides average publication rates (articles per year) for the three ranks. These figures confirm the intuitive expectation that publication rates increase by rank-a natural outcome of the fact that promotions to higher professorial ranks are often determined by superior publishing productivity. Using the overall sample standard deviation, the difference between the assistant and associate publication rates is statistically significant (alpha $=.05$ ), but the difference between associate and full professor rates is not. The higher publication rates of full professors also confirms a similar finding by Salimi and Perez (1995), who also found that full accounting professors often account for more than 50 percent of all the published research in their departments.

It is also useful to note that the publication rates in Table 6 also vary considerably within ranks. For example, the rates for associate professors ranged from a low value of .09 articles per year to a high value of 7.71 articles per year - an especially large range, given that the publication rates in each column are for faculty members in the same professorial rank. These large ranges likely reflect the large publication variances that can be observed in the research productivity of the underlying faculty population. The authors also suggest that such differences may stem from a myriad of underlying factors not controlled for in the sample. These items are discussed more fully in the Caveats section of the paper.

How do the figures in Table 6 compare to the research productivity of accounting faculty in other subdisciplines? Again, the most relevant statistics come from an earlier study by Englebrecht, et. al. (1994), which examined the publication rates of 584 promoted accounting faculty in the years 1987-1989. The computed averages for associate professors (at AACSB accredited institutions) in that study ranged from .61 articles per year (for associate professors in the years before promotion) to .99 articles per year (for the years surrounding their promotion decisions). The comparable values for full professors were .98 and 1.03 articles per year, respectively. Although these mean publication rates are fairly consistent with the publication rates computed for AIS faculty members in Table 6, it is also important to note that the rates computed in the Englebrecht study were limited to recently promoted faculty members.

\section{Gender Differentials}

Observations in a wide variety of disciplines have also noted gender differences in faculty publication rates (Davis, 2001, Streuly and Maranto, 1994, Dwyer, 1994, Lindley, et. al., 1992). Streuly and Maranto (1994) observe, for example, that male faculty members in other disciplines tend to publish more than their female counterparts, even when rank and other potentially-influential variables are taken into account. Do gender differences apply to AIS faculty as well? Table 7 provides an analysis of the survey respondents. 
Table 7: Average, Maximum, Minimum, and Median Publication Rates for AIS Faculty, by Gender

\begin{tabular}{|l|c|c|}
\hline & Males & Females \\
\hline Average: & 1.62 & 1.02 \\
\hline Maximum: & 7.71 & 4.00 \\
\hline Minimum: & 0.09 & 0.00 \\
\hline Median: & 1.09 & 1.00 \\
\hline
\end{tabular}

Table 7 shows that, on average, male AIS faculty members publish about fifty percent more articles per year than females-a statistically significant difference (for alpha $=.05$ ). Also, as might be expected in light of this statistic, both the maximum and minimum publication rates were higher for males than for females.

One reason why male faculty members appear to publish more articles, on average, than females is because some of the males in the current survey had very high publication rates-e.g., "7.71" articles per year for the most prolific male AIS faculty member in this survey and " 5.58 " articles per year for the second-most-prolific male faculty member. High productivity levels tend to skew the averages because the lower bound for these rates is zero but there is no upper bound for them. In the opinion of the authors, therefore, a more meaningful statistic is the median publication rate. As illustrated in Table 7, these median rates were nearly identical for the gender cohorts-i.e., "1.09" articles per year for male AIS faculty members and "1.00" articles per year for female AIS faculty members.

\section{Interpreting The Numbers}

What do these various publication rates mean? Given the wide diversity of the survey's respondents (and the fact that, as discussed below, a number of important influential factors were not controlled in the study), perhaps very little. Certainly the focus of this study was not to create publishing targets or requirements - a policy matter clearly the domain of local administrators.

This is not to say that the publication rats computed here are meaningless. For example, it may be reasonable for untenured AIS faculty to use the publication rate of "one blind-refereed article per year" to gauge their own research productivity when seeking tenure or promotion at AACSB-accredited schools. Similarly, such a value might also serve as a reasonable expectation for those review committees evaluating the research component of a candidate's tenure or promotion application.

\section{Textbook Preferences}

What textbooks do AIS educators use? Question 9 in the survey asked respondents to name the textbooks they used in their last AIS classes. Table 8 summarizes their responses, and includes the titles of all books receiving at least two citations. It suggests that the AIS textbook written by Romney and Steinbart is currently the most popular book in use, and that the second-most-popular AIS textbook was written by James Hall. Inasmuch as there is little consensus about what should be taught within AIS classes, perhaps it is not surprising that respondents are currently using a wide range of textbooks in the field. Given that the AIS field is relatively new and also one of the most dynamic in terms of changing technology, another implication of this finding is that there is ample opportunity for authors to write new works. 
Table 8: Textbook Preferences Of AIS Educators

\begin{tabular}{|c|c|}
\hline Textbook Author(s) & Number of Citations \\
\hline Romney and Steinbart & 12 \\
\hline Hall & 6 \\
\hline Perry and Schneider & 5 \\
\hline Galena and Sutton & 3 \\
\hline Arens and Ward & 2 \\
\hline Glover, et. al. & 2 \\
\hline Moscove, et. al. & 2 \\
\hline Wilkinson and Cenitto & 2 \\
\hline
\end{tabular}

\section{The Isolation Of The AIS Sub-Discipline}

Finally, a chance comment made by Professor William E. McCarthy about the "isolation of accounting information systems area" within the accounting discipline at the 2004 AIS Educator's Conference prompted the authors to ask a question about this in their survey. The exact wording of Question 15 was "Some faculty feel that the systems area is isolated, or not as well respected, as such 'mainstream' areas as managerial or financial accounting. Do you agree with this?"

Table 9 summarizes the responses to this question. In the survey, 27 respondents said "yes" 6 said "no," and 2 didn't know. Based on these responses, it appears that a clear majority of AIS faculty members feel that the AIS sub-discipline is isolated compared to other accounting sub-disciplines. This finding begs such questions as (1) "Does this matter?" and, if so, (2) "What can AIS professors do to overcome it?" The authors' perception is that these are currently open questions in the field.

Table 9: Is the AIS Sub-discipline Isolated within the Accounting Area?

\begin{tabular}{|c|c|}
\hline Response: & Number: \\
\hline Yes: & 27 \\
\hline No: & 6 \\
\hline Don't Know: & 2 \\
\hline
\end{tabular}

\section{CAVEATS}

The authors suggest that readers use extreme care when interpreting the data presented in this survey or applying its findings elsewhere. One consideration is the small sample size of the study-a total of 51 survey responses. This limitation is partially attributable to the small population from which the sample was dawn and appears to be a persistent problem when conducting research in the AIS area. For example, a recent study by Daigle and Arnold (2000) used observations from only 25 subjects, while a mass electronic mailing to 1,314 accounting academics by Lowe and Locke (2005) yielded only one AIS faculty member.

Another caveat is the fact that the respondents in this study were not randomly selected, but rather were volunteers who had chosen to participate in it. The comparisons to other studies that were provided in this paper suggest that the results reported here were not unreasonable. But the extent to which the results are accurately represent the underlying population can only be estimated.

The accuracy of the respondents' answers is also concern. The publishing data requested by this study were self reported by the survey respondents, for example, and the authors did not independently verify the accuracy of this information. Similarly, although they are commonly-used terms in AACSB-accredited accounting programs, this study did not formally define "first-tier" or "second-tier" journals in question 14, and this lack of specificity may have affected how respondents answered this question. 
As noted earlier, special care must be exercised when interpreting the publication rates computed in this study. The authors reiterate, for example, that their survey asked respondents for the number of blind-refereed articles they had published since acquiring their doctorates. This allowed respondents to include publications outside the AIS area or even the accounting discipline. The idea of allowing faculty to count such articles represents an unusual research tact - and to some, a troublesome concern. One counter argument is that, because the systems field is new, opportunities for publishing research in AIS-focused journals are limited. Another counterargument is that the interdisciplinary nature of the AIS field naturally leads authors to publication outlets outside accounting venues - an argument bolstered by this study's finding that many of the top AIS journals are not accounting journals.

The author's also note that allowing respondents to count articles outside the AIS area probably increased the publication rates computed here compared to those studies that limited such counts to articles published in the entries of approved journal lists. However, the authors also realize that there are many quality journals that are not blindrefereed and that technically were not included in this study - for example, many law journals — but whose articles may nonetheless be valued in promotion and tenure decisions. Not allowing survey respondents to count such articles has the effect of decreasing the publication rates reported here, although it is not known whether this in fact happened.

Closely related to the matter of "what articles to count" in any research productivity analysis is the question of "what adjustments to make?" For example, the authors did not distinguish between sole- and co-authored articles in this study - an important concern in the minds of some scholars (e.g., Hasselback, et. al., 2000). Similarly, this study did not adjust for the presence or absence of a Ph.D. program within the respondent's school, a factor that can affect research expectations, the availability of resources, teaching loads, and similar matters. Finally, the averages computed here did not factor "research quality" into the computations (other than the aforementioned requirement that articles be blind-refereed).

Lastly, the dynamic nature of the AIS discipline should also be considered. The availability of new journals, for example, can provide new publication outlets for researching faculty as well as alter the relative rankings of journal preferences constructed for them. Similarly, the popularity of new textbooks is likely to change the relative rankings of such works over time. Finally, over time, rising research expectations are likely to affect future measures of research productivity. At the authors' school, for example, a research record of one article per year is now considered a weak minimum for tenure rather than a sufficient condition for it. The authors' sense is that many schools have similarly increased their research expectations. This suggests that such matters as "journal preferences," "publication rates," and "tenure requirements" are best viewed as moving targets rather than static entities.

\section{SUMMARY AND CONCLUSIONS}

The literature about AIS faculty activities and interests is notable for its absence. Accordingly, the authors conducted a survey of instructors teaching AIS classes in AACSB-accredited accounting programs. One finding was that respondents ranked the Journal of Information Systems and the International Journal of Accounting Information Systems among the top three journals in the AIS area, but that several journals outside the discipline such as MIS Quarterly, Information Systems Research, and the Journal of Management Information Systems were also highly rated.

Another dimension of this study focused on tenure and promotion matters. In the answers to two additional questions in the survey concerning tenure decisions, a slight majority of the respondents thought it was necessary to publish articles in top-ranked journals in order to obtain tenure at their schools. Almost all the respondents felt it was necessary to publish in at least first- or second-tier journals to be promoted to full professor.

The authors also computed publication rates for the survey's respondents and found that the average respondent had published about one, blind-refereed article per year. A statistical analysis of these rates also revealed that associate and full professors published significantly more articles on average, than assistant professors. Further, although the average male AIS instructor publishes more than the average female AIS instructor, the median publication rates were almost identical — again at about one publication per year. The authors did not control for 
coauthorship, the presence of absence of a Ph.D. program, research quality, or a host of similar factors that usually affect this rate or how it is computed.

Two additional survey questions were concerned with textbook preferences and views about the potential isolation of the AIS sub-discipline within the accounting area. Regarding textbook preferences, there appeared to be little consensus about AIS book adoptions. This finding is consistent with earlier studies showing little agreement about what to teach in such courses, and therefore which books best meet the teaching needs of AIS faculty. In the current survey, the Romney and Steinbart text book was the most adopted, followed by an AIS textbook written by James Hall. Finally, a clear majority of survey respondents felt that the AIS area is isolated from the more "mainstream" accounting sub-disciplines. This finding begs such questions as "does this matter" and, if it does matter, "what can be done about it?"

\section{REFERENCES}

1. Anonymous, Delivering Tech-Savy Accountants The Practical Accountant, vol. 31, No. 9 (Sep, 1998), pp. 615.

2. Bodnar, George H., Auditing Information Systems: Model Curricula for Information Systems Auditing Internal Auditing vol. 14, no. 1 (Jan/Feb, 1999), pp. 40-45.

3. Buchheit, Steve, Denton Collins, and Austin Reitenga A Cross-Discipline Comparison of Top-Tier Academic Journal Publication Rates: 1997-1999 Journal of Accounting Education vol. 20, no. 2 (Spring, 2002), pp. 123-130.

4. Campbell, David R. and Robert G. Morgan, Publication Activity of Promoted Accounting Faculty, Issues in Accounting Education

5. Christensen, Anne L. Catherine A. Finger, and Claire K. Latham, New Accounting Scholars' Publications in Accounting and Nonaccounting Journals, Issues in Accounting Education vol. 17, no. 3 (Aug, 2002), pp. 233-238.

6. Daigle, Ronald J. and Vicky Arnold. An Analysis of the Research Productivity of AIS Faculty International Journal of Accounting Information Systems vol.1, no. 2 (Sept, 2000), pp. 106-122.

7. Davis, Joe C. The Scholarly Output of Economists: A Description of Publishing Patterns Atlantic Economic Journal vol. 29, no. 3 (Sept., 2001) pp. 341-350.

8. Dwyer, Peggy D. Gender Differences in the Scholarly Activities of Accounting Academics: An Empirical Investigation Issues in Accounting Education (Fall, 1994), pp. 231-243.

9. Englebrecht, Ted D., Govind S. Iyer, and Denise M. Patterson An Empirical Investigation of the Publication Productivity of Promoted Accounting Faculty Accounting Horizons (March, 1994), pp. 45-68.

10. Hasselback, James R., Alan Reinstein, and Edward S. Schwan Benchmarks for Evaluating the Research Productivity of Accounting Faculty The Journal of Accounting Education vol. 18 (June, 2000), pp. 79-97.

11. Hasselback, J. R., and Alan Reinstein A Proposal for Measuring Scholarly Productivity of Accounting Faculty Issues in Accounting Education (Fall, 1995), pp. 269-306.

12. Herron, Terri L. and Thomas W. Hall, Faculty Perceptions of Journals: Quality and Publishing Feasibility Journal of Accounting Education vol. 22, no. 3 (June, 2004), pp. 175-210.

13. Jackson, Robert B. and J. Owen Cherrington, IT Instruction Methodology and Minimum Competency for Accounting Students Information Executive vol. 6, no. 3 (May/Jun 2002), p. 13.

14. Jolly, Stephen A. Richard G. Schroeder, and Robert K. Spear An Empirical Investigation of the Relationship Between Journal Quality Ratings and Promotion and Tenure Decisions Accounting Educators' Journal vol. 7, no. 2 (1995), pp. 47-68.

15. Lindley, James T., Mary Fish, and John Jackson, Gender Differences in Salaries: An Application to Academe Southern Economic Journal vol. 59, no 2 (October, 1992), pp. 241-260.

16. Lont, David and Alan MacGregor, Integrating Information Technology Chartered Accountants Journal of New Zealand vol. 75, no. 3 (Apr, 1996), pp. 66-68.

17. Lowe, Alan and Joanne Locke, Perceptions of Journal Quality and Research Paradigm; Results of a Web Based Survey of British Accounting Academics Accounting, Organizations, and Society vol. 30, no. 1 (January, 2005), pp. 81-98. 
18. Maranto, Cheryl L. and Carolyn A. Streuly The Determinants of Accounting Professor's Publishing Productivity - the Early Career Contemporary Accounting Research (Spring, 1994), pp. 387-407.

19. Read, William J., D. V. Rama, and K. Raghunandan Are Publication Requirements for Accounting Faculty Promotions Still Increasing? Issues in Accounting Education (May, 1998), pp. 328-339.

20. Rowley, Thomas H. A Peer Evaluation of the Perceived Quality of Publication Outlets for Accounting Information Systems Journal of Information Systems vol. 5, no. 2 (Fall, 1991), pp. 50-61.

21. Salimi, Anwar Y. and F. Perez, Publication Productivity of Accounting Faculty Members at AACSB Accredited Schools, International Advances in Economic Research vol. 1, no. 4 (November, 1995), pp. $448 \mathrm{ff}$.

22. Schultz, Joseph J. Jr., Janet A. Meade, and Inder Khurana The Changing Roles of Teaching, Research, and Service in the Promotion and Tenure Decisions for Accounting Faculty Issues in Accounting Education (Spring, 1999), pp. 109-119.

23. Streuly, Carolyn A. and Cheryl L. Maranto Accounting Faculty Research Productivity and Citations: Are there Gender Differences? Issues in Accounting Education (Fall, 1994), pp. 247-255.

24. Theuri, Peter M. and Ruth Gunn, Accounting Information Systems Course Structure and Employer Systems Skills Expectations Journal of Accounting Education vol. 16, no. 1 (Winter, 1998), pp. 101-121.

25. Wilson, Laurie Baylor Initiates Integrated Accounting Core Baylor Business Review vol. 14, no 1 (Spring, 1996), p. 14.

26. Zivney, Terry L., William J. Bertin, and Thomas A. Gavin. A Comprehensive Examination of Accounting Faculty Publishing Issues in Accounting Education (Spring, 1995), pp. 1-10.

\section{APPENDIX A: SURVEY QUESTIONNAIRE}

1. What is your university affiliation? (e.g., "Univ. of Florida")

2. How long has it been since you received your doctorate? Years

Check here if no Ph.D.

3. What is your official title? $\square$ Adjunct Professor $\square$ Asst. Professor $\square$ Assoc. Professor $\square$ Full Professor $\checkmark$ Other (please indicate)

4. What is your gender? $\square$ Female $\square$ Male

5. How many articles have you published in blind-refereed journals since acquiring your doctorate? Articles

6.

A. What is your teaching area of accounting specialty? Check all that apply.

$\square$ AIS $\square$ Auditing $\square$ Financial $\square$ Managerial $\square$ Taxation

$\square$ Other (please specify:

B. What is your research area of accounting specialty? Check all that apply.

$\square$ AIS $\square$ Auditing $\square$ Financial $\square$ Managerial $\square$ Taxation

$\square$ Other (please specify:

7. What degrees are offered at your college? Please check all that apply.
$\square$ Bachelor's
$\square$ MBA $\square$ Master's in Accounting
$\square \mathrm{PhD} / \mathrm{DBA}$

8. Please name the three journals you consider most important in the AIS area. (Note: these can be practitioner or academic journals, and need not be accounting journals.) 
9. What textbook(s) did you last use in your AIS classes? Please list authors and titles (use back if necessary):

10. When applying for tenure at your school, how important is the quality of the journals in which an applicant has published? $\quad \square$ Not important $\square$ Somewhat important $\square$ Very important

11. When applying for promotion to full professor at your school, how important is the quality of the journals in which an applicant has published?
$\square$ Not important
$\square$ Somewhat important
$\square$ Very important

12. Given that manuscript submissions to journals are self-selective, does the acceptance rate of a journal affect your perception of its quality? $\quad \square$ Yes $\quad \square$ No

13. Can a tenure track faculty member get tenure at your school without publishing any articles in top-tier academic journals?

$\square$ Yes $\quad \square$ No

14. Can a tenure track faculty member get tenure at your school without publishing any articles in first- or second-tier academic journals?

$\square$ Yes $\quad \square$ No

15. Some AIS faculty feel that the systems area is isolated, or not as well respected, as such "mainstream" areas as managerial or financial accounting. Do you agree with this? $\square$ Yes $\quad \square$ No

Comments? 
NOTES 